\title{
Type 1 Diabetes Mellitus and Pernicious Anemia in an Elderly Japanese Patient: A Case Report and Literature Review
}

\author{
Nobumasa Ohara ${ }^{1}$, Masanori Kaneko ${ }^{1}$, Toshio Yano $^{2}$, Naoko Sato ${ }^{2}$, Hiroyuki Usuda ${ }^{3}$, \\ Masashi Miyakoshi ${ }^{4}$, Tatsuo Furukawa ${ }^{2}$, Tadashi Koike ${ }^{2}$, Kenzo Kaneko ${ }^{1}$ and Kyuzi Kamoi ${ }^{5}$
}

\begin{abstract}
We herein report the case of a 66-year-old Japanese man with acute-onset type 1 diabetes mellitus (T1D) accompanied by pernicious anemia. After 2 weeks of polyuria, the patient developed insulin-deficient hyperglycemia with diabetic ketoacidosis in the absence of verifiable islet-related autoantibodies and began insulin therapy in 2001. Eight years later, he developed gastric autoantibody-positive pernicious anemia and began methylcobalamin treatment. Previous studies have reported cases of slowly progressive autoimmune T1D concomitant with pernicious anemia. The present case suggests that potential associations with organ-specific autoimmune disorders should be considered during the long-term follow-up of T1D patients, even though verifiable islet-related autoantibodies are undetectable.
\end{abstract}

Key words: pernicious anemia, type 1 diabetes mellitus, insulin therapy, methylcobalamin, human leukocyte antigen, autoimmunity

(Intern Med 54: 2361-2365, 2015)

(DOI: 10.2169/internalmedicine.54.4621)

\section{Introduction}

Pernicious anemia is a macrocytic anemia caused by a vitamin B12 (cobalamin) deficiency that results from oxyntic gastric mucosa damage and intrinsic factor deficiency $(1,2)$. It is considered to be an autoimmune disorder due to the presence of gastric autoantibodies and is often associated with autoimmune thyroid diseases, and occasionally other organ-specific autoimmune disorders, such as type 1 diabetes mellitus (T1D) $(3,4)$.

T1D is a metabolic disease characterized by the destruction of pancreatic beta cells, which typically leads to an absolute deficiency in insulin secretion. It is a complex, heterogeneous disease, and depending on the manner of onset and progression, T1D is classified as acute-onset ("classical"), slowly progressive, or fulminant in Japan (5-9). Acute-onset T1D is characterized by the presence of diabetic ketoacidosis (DKA) at the time of diagnosis (clinical onset) and a lifelong insulin-dependent state thereafter.

Many cases of slowly progressive T1D concomitant with pernicious anemia have been reported, but only a few cases of fulminant or acute-onset T1D accompanied by pernicious anemia have been reported in Japan. We herein describe a patient with pernicious anemia that occurred 8 years after his diagnosis of acute-onset T1D. In addition, all 14 previously reported cases of Japanese patients with concomitant T1D and pernicious anemia are reviewed (10-23).

\section{Case Report}

A 66-year-old Japanese man with disturbed consciousness was admitted to our hospital in August 2001. His medical and family histories were unremarkable, and he had been healthy until an episode of a sore throat and a fever that occurred 2 weeks prior to admission. Several days later he de-

\footnotetext{
${ }^{1}$ Department of Endocrinology and Metabolism, Nagaoka Red Cross Hospital, Japan, ${ }^{2}$ Department of Hematology, Nagaoka Red Cross Hospital, Japan, ${ }^{3}$ Department of Pathology, Nagaoka Red Cross Hospital, Japan, ${ }^{4}$ Tsutsui Medical Clinic, Japan and ${ }^{5}$ Center of Diabetes, Endocrinology and Metabolism, Joetsu General Hospital, Japan

Received for publication December 2, 2014; Accepted for publication January 27, 2015

Correspondence to Dr. Nobumasa Ohara, oharan@med.niigata-u.ac.jp
} 
veloped thirst and polyuria. The patient was $155 \mathrm{~cm}$ in height and weighed $56 \mathrm{~kg}$. His body temperature was 36.8 ${ }^{\circ} \mathrm{C}$, his oral cavity was dry, and his blood pressure and pulse rate were 120/74 $\mathrm{mmHg}$ and 109 beats per minute, respectively. The laboratory findings revealed the presence of DKA (arterial pH 7.21, partial carbon dioxide pressure 19.1 $\mathrm{mmHg}$, partial oxygen pressure $115.0 \mathrm{mmHg}$, bicarbonate $7.6 \mathrm{mmol} / \mathrm{L}$, plasma glucose $51.4 \mathrm{mmol} / \mathrm{L}$, urinary ketone bodies positive), a high HbA1c (National Glycohemoglobin Standardization Program, NGSP) value of $9.0 \%$ (24), and elevated serum amylase levels (331 IU/L). Tests for glutamic acid decarboxylase antibody (GADA) $(<1.3 \mathrm{U} / \mathrm{mL})$ and islet cell antibody (ICA) were both negative. Abdominal ultrasonography detected fatty deposition in the liver, but no abnormalities in the pancreas or kidneys were found. Following the correction of DKA using intravenous insulin and saline therapy, the patient regained normal consciousness and provided six consecutive urinary C-peptide excretions of 1.6, $0.1,3.8,14.1,14.6$, and $6.8 \mu \mathrm{g} /$ day (mean value: $6.8 \mu \mathrm{g}$ / day). He was diagnosed with acute-onset T1D, began insulin injection therapy, and was discharged in September 2001 without complications after completing a self-management diabetes education program.

The patient was followed up at the outpatient clinic of our hospital and was taking multiple daily injections of insulin lispro and human isophane insulin (a total of 48 units/ day) which provided excellent glycemic control [HbA1c (NGSP) level: -6.6\%]. The patient's complete blood cell count showed no abnormalities in June 2008 (red blood cells $448 \times 10^{4} / \mu \mathrm{L}$, hemoglobin $13.6 \mathrm{~g} / \mathrm{dL}$, hematocrit $39.3 \%$, white blood cells $7,200 / \mu \mathrm{L}$, and platelets $34.5 \times 10^{4} / \mu \mathrm{L}$ ).

In October 2009, the patient was 74 years of age when he was admitted to our hospital with complaints of appetite loss and dysgeusia over the preceding 3 weeks. A physical examination revealed that he had pallor, anemic palpebral conjunctiva, a body temperature of $36.3^{\circ} \mathrm{C}$, a blood pressure of $126 / 64 \mathrm{mmHg}$, and a regular pulse rate of 90 beats per minute. No struma, chest rales, heart murmurs, skin abnormalities, and palpable lymph node or spleen enlargements were detected, and the patient's deep tendon reflexes were normal. A complete blood cell count detected macrocytic anemia with anisocytes and poikilocytes (red blood cells $196 \times 10^{4} / \mu \mathrm{L}$, hemoglobin $8.5 \mathrm{~g} / \mathrm{dL}$, hematocrit $24.0 \%$, mean corpuscular volume $122.4 \mathrm{fL}$, reticulocytes $0.9 \%$, white blood cells $3,500 / \mu \mathrm{L}$, and platelets $\left.12.3 \times 10^{4} / \mu \mathrm{L}\right)$. His plasma glucose, serum C-peptide, and HbA1c (NGSP) levels were $10.1 \mathrm{mmol} / \mathrm{L},<0.2 \mathrm{ng} / \mathrm{mL}$, and $6.2 \%$, respectively. The serum total bilirubin $(3.4 \mathrm{mg} / \mathrm{dL})$, aspartate aminotransferase (68 IU/L), alanine aminotransferase (49 IU/L), and lactate dehydrogenase $(3,274 \mathrm{IU} / \mathrm{L})$ levels were high, but the serum iron $(168 \mu \mathrm{g} / \mathrm{dL})$, ferritin $(225 \mathrm{ng} / \mathrm{mL})$, unsaturated iron binding capacity $(52 \mu \mathrm{g} / \mathrm{dL})$, and folic acid $(12.2 \mathrm{ng} / \mathrm{mL})$ levels were normal. Both the direct and indirect Coombs tests were negative, but his serum vitamin B12 $(86 \mathrm{pg} / \mathrm{mL}$, reference range: $233-914 \mathrm{pg} / \mathrm{mL})$ and haptoglobin $(<10 \mathrm{mg} /$ dL) levels were low. An abdominal computed tomography scan showed no abnormalities in the liver, bile duct, spleen, pancreas, or kidneys, but upper gastrointestinal endoscopy in conjunction with a histological examination revealed atrophic body gastritis. No polypoid lesions or evidence of gastric carcinoid tumors were detected. The serum antiHelicobacter pylori antibody test $(<3 \mathrm{U} / \mathrm{mL})$ was negative, but anti-gastric parietal cells antibody (titer 1:80, reference range: titer <1:10) and anti-intrinsic factor antibody were both positive. According to these results, the patient was diagnosed with autoimmune gastritis and pernicious anemia.

The patient had normal pituitary, thyroid, and adrenal functions and tested negative for autoantibodies against pituitary cells, thyrotropin receptor $(<1.0 \mathrm{IU} / \mathrm{L})$, thyroid peroxidase $(<0.3 \mathrm{U} / \mathrm{mL})$, thyroglobulin $(<0.3 \mathrm{U} / \mathrm{mL})$, and adrenal cortex (titer $<1: 10)$. In addition, tests for anti-nuclear antibody (titer $<1: 40)$ and rheumatoid factor $(<5 \mathrm{IU} / \mathrm{mL})$ were both negative. Human leukocyte antigen (HLA) typing showed the presence of $A^{*} 24: 02 / 33: 03, B^{*} 54: 01 / 58: 01$, and $\mathrm{C}^{*}$ 01:02/03:02 class I genes and DRB1*04:05/13:02, DQB1* 04:01/06:09, and DQA1*01:02/03:03 class II genes.

The patient began a regimen of the intramuscular administration of methylcobalamin, and his appetite loss and dysgeusia resolved within a few days. Two weeks later, the laboratory tests performed showed an improvement in anemia (red blood cells $271 \times 10^{4} / \mu \mathrm{L}$, hemoglobin $9.0 \mathrm{~g} / \mathrm{dL}$, and hematocrit $30.8 \%$ ) and normalization of serum levels of total bilirubin $(0.4 \mathrm{mg} / \mathrm{dL})$, aspartate aminotransferase (37 IU/ L), alanine aminotransferase (39 IU/L), and lactate dehydrogenase $(211 \mathrm{IU} / \mathrm{L})$. The patient was discharged on day 22 of hospitalization, and one month later his blood cell count had normalized (red blood cells $474 \times 10^{4} / \mu \mathrm{L}$, hemoglobin $13.0 \mathrm{~g} /$ $\mathrm{dL}$, hematocrit $41.8 \%$, white blood cells $5,800 / \mu \mathrm{L}$, and platelets $\left.33.9 \times 10^{4} / \mu \mathrm{L}\right)$.

The patient continued a therapeutic regimen of methylcobalamin replacement (500 $\mu \mathrm{g} / 3$ months) and injections of insulin lispro and insulin glargine (a total of 42 units/day) at the outpatient clinic. In September 2014, the laboratory examinations showed normal values for a complete blood count, an HbA1c (NGSP) level of $6.8 \%$, undetectable serum C-peptide levels, and negative test results for autoantibodies against the pituitary, thyroid, and adrenal glands. The subsequent clinical course of the patient has been uneventful, and there have been no occurrences of additional autoimmune disorders or stomach malignancies related to autoimmune gastritis.

\section{Discussion}

An elderly Japanese man developed DKA approximately 10 days after the occurrence of hyperglycemic symptoms, and presented to our hospital in an insulin-dependent state. These findings were consistent with a definitive diagnosis of acute-onset T1D (9); the presence of the HLA-A*24, B*54, DRB1*04:05, DQA1*03:03, and DQB1*04:01 genes further supported this diagnosis (25-28). In addition, although the patient did not fulfill the diagnostic criteria for fulminant 
Table. Summary of Reported Japanese Patients who Presented with Concomitant Pernicious Anemia and Type 1 Diabetes Mellitus.

\begin{tabular}{|c|c|c|c|c|c|c|c|c|c|c|c|}
\hline \multirow[b]{2}{*}{ Case } & \multirow[b]{2}{*}{ Sex } & \multirow[b]{2}{*}{ *HLA-DR } & \multirow[b]{2}{*}{ *HLA-DQ } & \multicolumn{4}{|c|}{ Type 1 diabetes mellitus } & \multicolumn{2}{|c|}{ Pernicious anemia } & \multirow[b]{2}{*}{$\begin{array}{l}\text { Other autoimmune } \\
\text { disorders }\end{array}$} & \multirow[b]{2}{*}{ Reference } \\
\hline & & & & $\begin{array}{c}\text { Age at } \\
\text { diabetes } \\
\text { onset (year) }\end{array}$ & $\begin{array}{l}\text { DKA at } \\
\text { diagnosis }\end{array}$ & $\begin{array}{l}* * \text { Islet-related } \\
\text { autoantibodies }\end{array}$ & $* * *$ Subtype & $\begin{array}{l}\text { Age at } \\
\text { onset } \\
\text { (year) }\end{array}$ & $\begin{array}{c}* * * * \text { Gastric } \\
\text { autoantibodies }\end{array}$ & & \\
\hline 1 & Male & N/A & $\mathrm{N} / \mathrm{A}$ & 28 & $(+)$ & $\mathrm{N} / \mathrm{A}$ & Undetermined & 30 & Positive & $(-)$ & 10 \\
\hline 2 & Male & $\mathrm{N} / \mathrm{A}$ & N/A & 5 & $(+)$ & N/A & Acute-onset & 8 & N/A & Hashimoto's disease & 11 \\
\hline 3 & Female & 8 & N/A & 6 & $(+)$ & Negative & Undetermined & 19 & Positive & $\begin{array}{c}\text { ITP } \\
\text { Autoimmune neutropenia }\end{array}$ & 12 \\
\hline 4 & Female & 4 & 3,4 & 60 & $(-)$ & Positive & $\begin{array}{c}\text { Slowly } \\
\text { progressive }\end{array}$ & 72 & Positive & $(-)$ & 13 \\
\hline 6 & Male & N/A & N/A & 73 & $(-)$ & Positive & $\begin{array}{l}\text { Slowly } \\
\text { progressive }\end{array}$ & 83 & Positive & Hashimoto's disease & 15 \\
\hline 7 & Female & $\begin{array}{c}{[\mathrm{DRB} 1 *} \\
08: 02 / 15: 02]\end{array}$ & $\begin{array}{c}{[\mathrm{DQB} 1 *} \\
04: 02 / 06: 01]\end{array}$ & 58 & $(-)$ & Positive & $\begin{array}{l}\text { Slowly } \\
\text { progressive }\end{array}$ & 59 & Positive & Hashimoto's disease & 16 \\
\hline 8 & Female & 4,13 & NA & 58 & $(-)$ & Positive & $\begin{array}{l}\text { Slowly } \\
\text { progressive }\end{array}$ & 81 & Positive & $\begin{array}{l}\text { Vitiligo vulgaris } \\
\text { Hashimoto's disease }\end{array}$ & 17 \\
\hline 9 & Female & $\begin{array}{c}{\left[\mathrm{DRB} 1^{*}\right.} \\
15: 01 / 15: 02]\end{array}$ & $\begin{array}{c}\text { [DQB1* } \\
\text { 06:01/06:02] }\end{array}$ & 53 & $(-)$ & Positive & $\begin{array}{l}\text { Slowly } \\
\text { progressive }\end{array}$ & 61 & Positive & $\begin{array}{c}\text { ITP } \\
\text { Hashimoto's disease }\end{array}$ & 18 \\
\hline 11 & Female & 13,15 & N/A & 70 & $(-)$ & Positive & $\begin{array}{c}\text { Slowly } \\
\text { progressive }\end{array}$ & 64 & Positive & Hashimoto's disease & 20 \\
\hline 12 & Male & 4 & N/A & 59 & $(-)$ & Positive & $\begin{array}{l}\text { Slowly } \\
\text { progressive }\end{array}$ & 59 & Positive & $(-)$ & 21 \\
\hline 13 & Female & $\begin{array}{c}{[\mathrm{DRB} 1 *} \\
04: 05 / 04: 06]\end{array}$ & $\begin{array}{c}{[\mathrm{DQB} 1 *} \\
03: 02 / 04: 01]\end{array}$ & 75 & $(-)$ & Positive & $\begin{array}{l}\text { Slowly } \\
\text { progressive }\end{array}$ & 81 & Positive & Hashimoto's disease & 22 \\
\hline 14 & Female & $\begin{array}{c}{\left[\mathrm{DRB} 1^{*}\right.} \\
11: 01 / 15: 02]\end{array}$ & $\begin{array}{c}{\left[\mathrm{DQB} 1^{*}\right.} \\
03: 01 / 06: 01]\end{array}$ & 71 & NA & Positive & Undetermined & 73 & Positive & Hashimoto's disease & 23 \\
\hline$\circ$ & Male & $\begin{array}{c}{[\mathrm{DRB} 1 *} \\
04: 05 / 13: 02]\end{array}$ & $\begin{array}{c}{[\mathrm{DQB} 1 *} \\
04: 01 / 06: 09]\end{array}$ & 66 & $(+)$ & Negative & Acute-onset & 74 & Positive & $(-)$ & $\begin{array}{l}\text { Present } \\
\text { case }\end{array}$ \\
\hline
\end{tabular}

*Human leukocyte antigen (HLA)-DRB1 and HLA-DQB1 genotypes are shown in square brackets.

**Positive islet-related autoantibodies were defined by a positive test for one or more antibodies against glutamic acid decarboxylase, islet cells, or insulinoma-associated antigen 2 at any time during the course of diabetes and/or a positive insulin antibody test at onset.

***Type 1 diabetes mellitus was categorized as fulminant, acute-onset, or slowly progressive based on published criteria (7-9). The subtypes in cases 1,

3 , and 14 were undetermined because of a lack of information regarding the duration of hyperglycemic symptoms prior to diabetic ketoacidosis (DKA)

$(10,12)$ and the presence or absence of DKA at onset $(23)$.

****Positive gastric autoantibodies were defined by a positive test for one or two antibodies against intrinsic factors or parietal cells.

N/A: not available, ITP: idiopathic thrombocytopenic purpura

T1D (8) because his HbA1c (NGSP) value was higher than $8.7 \%$ at the first visit, the patient presented with several characteristic features of this disorder, including a prodrome of flu-like symptoms, very low C-peptide levels, elevated serum pancreatic enzyme levels, a fatty liver at disease onset, and a negative test for islet-related autoantibodies (29).

T1D is considered to be an organ-specific autoimmune disorder, and many patients with acute-onset T1D, similarly to those with slowly progressive T1D, have autoantibodies against islet antigens in the early phase of the disease $(5,6,9)$; these are typically referred to as autoimmune cases. The major autoantibodies of clinical and research interest include ICA, GADA, insulinoma-associated antigen-2 antibody, insulin autoantibody, and ZnT8 antibody; however, the sensitivity of each marker is still less than $80 \%$ (30), and a subset of patients with acute-onset T1D are autoantibody-negative (idiopathic cases) (9). In addition, if present, these autoantibody titers may decline and even disappear over time (30). The present patient tested negative for ICA and GADA at the onset of T1D and was therefore considered to be an idiopathic case of T1D. At the same time, however, he was considered to exhibit an autoimmune destruction of islet beta cells in the absence of verifiable islet-related autoantibodies, which would be classified as autoimmune T1D.

The patient developed pernicious anemia 8 years after the onset of T1D. Table presents a summary of previously reported Japanese cases that exhibited concurrent pernicious anemia and T1D. These cases included patients of all ages and both genders, however, most are older woman. The patients tended to exhibit T1D prior to pernicious anemia, with a time lag of up to approximately 10 years, and many were diagnosed with slowly progressive T1D. The present patient is the first reported adult case exhibiting established acuteonset T1D accompanied by pernicious anemia.

In countries with Caucasian populations, T1D is broadly divided into two forms: rapid onset or slow progression $(31,32)$. In general, the rapid onset subtype is referred to simply as T1D. The slow progression subtype is referred to as latent autoimmune diabetes in adults, and it has clinical features similar to those of the slowly progressive T1D subtype in Japan $(6,31,32)$. In contrast to studies in Japanese patients, many studies of T1D Caucasian patients found a high prevalence of pernicious anemia as part of polyglandular autoimmune syndrome (PGAS) (1-4, 33-36). Additionally, genetic research has revealed that the genotypes HLADRB $1^{*} 03$ and DRB $1^{*} 04$ predispose patients to pernicious anemia associated with T1D and autoimmune thyroid dis- 
eases $(2,3,36,37)$. In the present case, the patient had the HLA class II haplotype DRB1 04:05-DQA1*03:03-DQB1 ${ }^{*}$ 04:01, which increases the susceptibility of Japanese individuals to PGAS (38). Therefore, associated autoimmunity may have played a role in the development of both T1D and pernicious anemia in the present case.

Among previously reported Japanese cases of concomitant T1D and pernicious anemia (Table), most patients had autoimmune T1D and gastric autoantibody-positive pernicious anemia either with or without autoimmune thyroid diseases, and thus, were considered to be affected by PGAS type 3 or 4 (38). There have been 2 reported cases of idiopathic T1D that exhibited a variety of organ-specific autoimmune disorders in addition to pernicious anemia, and had a time lag that was over 10-20 years from the onset of T1D $(12,19)$. In the present case, although the patient did not exhibit any autoimmune disorders other than pernicious anemia during the 13 years after the onset of T1D, careful long-term follow-up assessments may be needed to monitor the potential occurrence of additional organ-specific autoimmune disorders.

In conclusion, we herein reported an elderly Japanese man who developed pernicious anemia 8 years after the diagnosis of acute-onset T1D. This case suggests that potential comorbidities of organ-specific autoimmune disorders, including pernicious anemia, should be considered in T1D patients throughout an extended follow-up period, even though verifiable islet-related autoantibodies are not detected.

The authors state that they have no Conflict of Interest (COI).

\section{Acknowledgement}

We thank the medical laboratory technicians of Nagaoka Red Cross Hospital for their helpful technical support. We also thank Dr Hirohito Sone for his helpful advice.

\section{References}

1. Toh BH, van Driel IR, Gleeson PA. Pernicious anemia. N Engl J Med 337: 1441-1448, 1997.

2. Lahner E, Annibale B. Pernicious anemia: new insights from a gastroenterological point of view. World J Gastroenterol 15: 51215128, 2009.

3. Bizzaro N, Antico A. Diagnosis and classification of pernicious anemia. Autoimmun Rev 13: 565-568, 2014.

4. Perros P, Singh RK, Ludlam CA, Frier BM. Prevalence of pernicious anaemia in patients with Type 1 diabetes mellitus and autoimmune thyroid disease. Diabet Med 17: 749-751, 2000.

5. Kawasaki E, Matsuura N, Eguchi K. Type 1 diabetes in Japan. Diabetologia 49: 828-836, 2006.

6. Kobayashi $\mathrm{T}$, Tamemoto $\mathrm{K}$, Nakanishi $\mathrm{K}$, et al. Immunogenetic and clinical characterization of slowly progressive IDDM. Diabetes Care 16: 780-788, 1993.

7. Committee of the Japan Diabetes Society on Type 1 Diabetes. Diagnostic criteria for slowly progressive insulin-dependent (type 1) diabetes mellitus (SPDDIM) (2012): report by the Committee on Slowly Progressive Insulin-dependent (Type 1) Diabetes Mellitus of the Japan Diabetes Society. Tonyobyo (J Japan Diab Soc) 56: 590-597, 2013 (in Japanese, Abstract in English).

8. Imagawa $A$, Hanafusa $T$, Awata $T$, et al. Report of the committee of the Japan Diabetes Society on the research of fulminant and acute-onset type 1 diabetes mellitus: new diagnostic criteria for fulminant type 1 diabetes mellitus (2012). J Diabetes Investig 3: 536-539, 2012.

9. Kawasaki E, Maruyama T, Imagawa A, et al. Diagnostic criteria for acute-onset type 1 diabetes mellitus (2012): report of the Committee of Japan Diabetes Society on the Research of Fulminant and Acute-onset Type 1 Diabetes Mellitus. J Diabetes Investig 5: 115-118, 2014.

10. Kanayama M, Abe T. Diabetes mellitus associated with pernicious anemia. Tonyobyo To Taisha (Diabetes Journal) 3: 189-192, 1975 (in Japanese).

11. Minowa $S$, Mori $O$, Miwa $K$, Iwamura $H$, Yazawa $T$, Ogawa M. A case of insulin-dependent diabetes mellitus associated with pernicious anemia. Nihon Shonika Gakkai Zasshi (Acta Paediatrica Japonica) 88: 719-725, 1984 (in Japanese).

12. Goto Y, Arai I, Ichinose M, Kinoshita K, Narishima M. A case of insulin dependent diabetes mellitus followed by pernicious anemia and idiopathic thrombocytopenic purpura. Tonyobyo To Taisha (Diabetes Journal) 16: 24-32, 1988 (in Japanese).

13. Kamoi K, Soga N, Takagi M. ICA-positive diabetes mellitus with pernicious anemia in an elderly woman. Tonyobyo (J Japan Diab Soc) 39: 47-51, 1996 (in Japanese, Abstract in English).

14. Takebe N, Fujimaru K, Matsubara K, et al. GAD antibodypositive slowly progressive insulin-dependent diabetes mellitus associated with pernicious anemia: a case report. Tonyobyo (J Japan Diab Soc) 43: 367-371, 2000 (in Japanese, Abstract in English).

15. Morita H, Yamada K, Wada Y, et al. Slowly progressive type 1 diabetes mellitus accompanied by chronic thyroiditis in an elderly patient with pernicious anemia. Tonyobyo (J Japan Diab Soc) 44: 831-836, 2001 (in Japanese).

16. Kobayashi M, Hamanishi T, Tamai M, et al. A case of slowly progressive type 1 diabetes mellitus with pernicious anemia and chronic thyroiditis. Tonyobyo (J Japan Diab Soc) 47: 123-128, 2004 (in Japanese, Abstract in English).

17. Suzuki C, Hirai Y, Terui K, Kohsaka A, Akagi T, Suda T. Slowly progressive type 1 diabetes mellitus associated with vitiligo vulgaris, chronic thyroiditis, and pernicious anemia. Intern Med $\mathbf{4 3}$ : 1183-1185, 2004.

18. Ogawa N, Tanaka J, Yamane Y, et al. Autoimmune polyglandular syndrome type III associated with slowly progressive type 1 diabetes mellitus, chronic thyroiditis, pernicious anemia and idiopathic thrombocytopenic purpura: A case report. Tonyobyo (J Japan Diab Soc) 49: 723-729, 2006 (in Japanese, Abstract in English).

19. Inoue T, Hirase N, Ichino I, Tanaka S, Haji M. Pure red cell aplasia and type 1 diabetes in a patient with myasthemia gravis, thymoma, and pernicious anemia. Tonyobyo (J Japan Diab Soc) 52: 703-707, 2009 (in Japanese).

20. Nagase R, Kishimoto T. A case of autoimmune polyglandular syndrome with type 1 diabetes in a patient with treated pernicious anemia and type 2 diabetes. Tonyobyo (J Japan Diab Soc) 53: 755-759, 2010 (in Japanese).

21. Kinoshita J, Hata S, Yamazaki H, Tajima N. Slowly progressive insulin-dependent diabetes mellitus associated with pernicious anemia. Intern Med 49: 155-159, 2010.

22. Hidaka S, Kawabata Y, Nakayama T, et al. A case of polyglandular autoimmune syndrome type III-A and myelodysplasic syndrome with a strong family history of autoimmune thyroid diseases. Tonyobyo (J Japan Diab Soc) 56: 15-23, 2013 (in Japanese, Abstract in English).

23. Murai $H$, Yamamoto $T$, Azuma $D$, et al. A case of autoimmune polyglandular syndrome type III diagnosed based on the detection of pernicious anemia associated with type 1 diabetes mellitus and chronic thyroiditis. Tonyobyo (J Japan Diab Soc) 57: 797-804, 2014 (in Japanese, Abstract in English).

24. Committee on the Standardization of Diabetes Mellitus-Related 
Laboratory Testing of Japan Diabetes Society. International clinical harmonization of glycated hemoglobin in Japan: from Japan Diabetes Society to National Glycohemoglobin Standardization Program values. J Diabetes Invest 3: 39-40, 2012.

25. Nakanishi K, Kobayashi T, Murase T, Naruse T, Nose Y, Inoko H. Human leukocyte antigen-A24 and -DQA1"0301 in Japanese insulin-dependent diabetes mellitus: independent contributions to susceptibility to the disease and additive contributions to acceleration of beta-cell destruction. J Clin Endocrinol Metab 84: 3721$3725,1999$.

26. Hamaguchi K, Kimura A, Seki N, et al. Analysis of tumor necrosis factor-alpha promoter polymorphism in type 1 diabetes: HLA$\mathrm{B}$ and -DRB1 alleles are primarily associated with the disease in Japanese. Tissue Antigens 55: 10-16, 2000.

27. Tanaka S, Kobayashi T, Nakanishi K, et al. Association of HLADQ genotype in autoantibody-negative and rapid-onset type 1 diabetes. Diabetes Care 25: 2302-2307, 2002.

28. Committee on Type 1 Diabetes, Japan Diabetes Society. Differential association of HLA with three subtypes of type 1 diabetes: fulminant, slowly progressive and acute-onset. Diabetologia 52: 2513-2521, 2009

29. Imagawa A, Hanafusa T. Fulminant type 1 diabetes mellitus. Endocr J 53: 577-584, 2006.

30. Winter WE, Schatz DA. Autoimmune markers in diabetes. Clin
Chem 57: 168-175, 2011.

31. Naik RG, Brooks-Worrell BM, Palmer JP. Latent autoimmune diabetes in adults. J Clin Endocrinol Metab 94: 4635-4644, 2009.

32. Merger SR, Leslie RD, Boehm BO. The broad clinical phenotype of Type 1 diabetes at presentation. Diabet Med 30: 170-178, 2013.

33. Davis RE, McCann VJ, Stanton KG. Type 1 diabetes and latent pernicious anaemia. Med J Aust 156: 160-162, 1992.

34. De Block CE, De Leeuw IH, Van Gaal LF. Autoimmune gastritis in type 1 diabetes: a clinically oriented review. J Clin Endocrinol Metab 93: 363-371, 2008.

35. Tzellos TG, Tahmatzidis DK, Lallas A, Apostolidou K, Goulis DG. Pernicious anemia in a patient with Type 1 diabetes mellitus and alopecia areata universalis. J Diabetes Complications 23: 434437, 2009.

36. Cutolo M. Autoimmune polyendocrine syndromes. Autoimmun Rev 13: 85-89, 2014.

37. Ungar B, Mathews JD, Tait BD, Cowling DC. HLA-DR patterns in pernicious anaemia. Br Med J (Clin Res Ed) 282: 768-770, 1981.

38. Hashimoto K, Maruyama H, Nishiyama M, et al. Susceptibility alleles and haplotypes of human leukocyte antigen DRB1, DQA1, and DQB1 in autoimmune polyglandular syndrome type III in Japanese population. Horm Res 64: 253-260, 2005.

(C) 2015 The Japanese Society of Internal Medicine http://www.naika.or.jp/imonline/index.html 